\title{
Conformational stability of DNA in hydrated ionic liquid by synchrotron- based UV resonance raman
}

C. Bottari, I. Mancini, A. Mele, A. Gessini, C. Masciovecchio, et al.

C. Bottari, I. Mancini, A. Mele, A. Gessini, C. Masciovecchio, B. Rossi, "Conformational stability of DNA in hydrated ionic liquid by synchrotron-based UV resonance raman," Proc. SPIE 11086, UV and Higher Energy Photonics: From Materials to Applications 2019, 110860Q (9 September 2019); doi: $10.1117 / 12.2529077$

Event: SPIE Nanoscience + Engineering, 2019, San Diego, California, United States 


\title{
Conformational stability of DNA in hydrated ionic liquid by synchrotron-based UV Resonance Raman
}

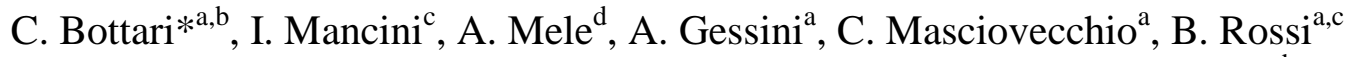 \\ ${ }^{a}$ Elettra-Sincrotrone Trieste, S.S. 114 km 163.5, Basovizza, 34149, Trieste, Italy; ${ }^{b}$ Dept. of \\ Physics, University of Trieste, Via A. Valerio 2, 34127, Trieste, Italy; ${ }^{\circ}$ Dept. of of Physics, \\ University of Trento, Via Sommarive, 14 - 38123 Povo Trento, Italy; ${ }^{\mathrm{d}}$ Dept. of of Chemistry, \\ Materials and Chemical Engineering 'G. Natta", Politecnico di Milano and INSTM Local Unit, \\ Piazza L. da Vinci 32, 20133, Milano, Italy
}

\begin{abstract}
Although Deoxyribonucleic acid (DNA) is considered substantially stable in aqueous solution, slow hydrolysis can damage its double-helix structure and cause denaturation when it is stored for several months. Therefore, the design of aqueous solvents that are able to stabilize and maintain DNA conformation is a challenging issue. Ionic liquids (ILs) appear as ideal water co-solvents for DNA biotechnology due to their unique properties. We have investigated the thermal stability of DNA in 1-butyl-3-methylimidazolium aqueous solutions by synchrotron-based UV Resonance Raman (UVRR) spectroscopy with the aim to clarify the role played by concentration of IL in stabilizing the DNA natural conformation. The synchrotron-based UV source for UVRR measurements allows us to enhance specific vibrational signals associated to nitrogenous bases of DNA, through an appropriate tuning of the excitation wavelength. Such approach permits to probe the rearrangements in the local environment around specific nucleotides as a function of thermal conditions.
\end{abstract}

Keywords: UV Resonance Raman scattering, DNA, ionic liquid, melting transition

*cettina.bottari@elettra.eu; +390403758516

\section{INTRODUCTION}

Deoxyribonucleic acid (DNA) is a macromolecule of pivotal biological role thanks to its ability to store the genetic instructions for the growth, functioning and development in the cell. It plays key role in many biological processes, i.e. gene expression transcription and carcinogenesis ${ }^{1}$. Due to its properties together with its chiral structure ${ }^{2}$, DNA represents a key component in pharmaceutical and biomedical studies and a crucial material in the development of advanced molecular device ${ }^{3,4}$. From a structural point of view, DNA is composed of two linear stands of nucleotides that coil around each other to form the characteristic double helix structure. Each nucleotide is composed by a phosphate group, a deoxyribose monosaccharidic unit and one of the four nucleobases (cytosine, guanine, adenine and thymine). The nucleobases of the two chains interact by H-bond, according to the base-pairing rules, connecting the two sugar-phosphate backbones. Figure 1 reports a representative chemical structures of DNA for two WatsonCrick base-pairs with the conventions adopted for the numbering of atoms. Although DNA is considered stable in aqueous solution, slow hydrolytic reactions such as deamination and depurination may denature the double helical DNA conformation ${ }^{5}$ For this reason, a growing interest has been devoted to the development of suitable aqueous solvents able to improve the stabilization of $\mathrm{DNA}^{6,7}$. This could open the possibility to maintain the native DNA structure for a long period and in critical conditions, such as high temperature and pressure ${ }^{8}$.

Ionic liquids (ILs) have proven to be the preferred solvents to replace the traditional organic solvents and/or aqueous solution in many types of reactions ${ }^{9,10}$. They are composed by anions and organic cations whose structure is such to make the lattice enthalpy low, thus resulting in low melting points. They are characterized by interesting properties such as negligible vapor pressure, non-flammability, high thermal and chemical stability and low toxicity ${ }^{11,12}$. Based on these peculiarities, ILs find applications in organic synthesis ${ }^{13}$, electrochemical devices ${ }^{14}$, photochemical cells ${ }^{15}$, ${ }^{16}$ and catalysis ${ }^{17}$. During the last years, the application of ILs to DNA technology has received particularly attention. For instance, in literature it is reported the use of ILs for the extraction of trace amount of DNA from the aqueous solution $^{10}$, for slowing DNA translocation through nanopores ${ }^{18}$ and for the DNA storage ${ }^{19}$. All such applications are strongly dependent on the interaction at molecular level between ILs and DNA. A basic understanding of IL-DNA

UV and Higher Energy Photonics: From Materials to Applications 2019, edited by Gilles Lérondel,

Yong-Hoon Cho, Atsushi Taguchi, Satoshi Kawata, Proc. of SPIE Vol. 11086, 110860Q

(C) 2019 SPIE · CCC code: 0277-786X/19/\$21 - doi: 10.1117/12.2529077 


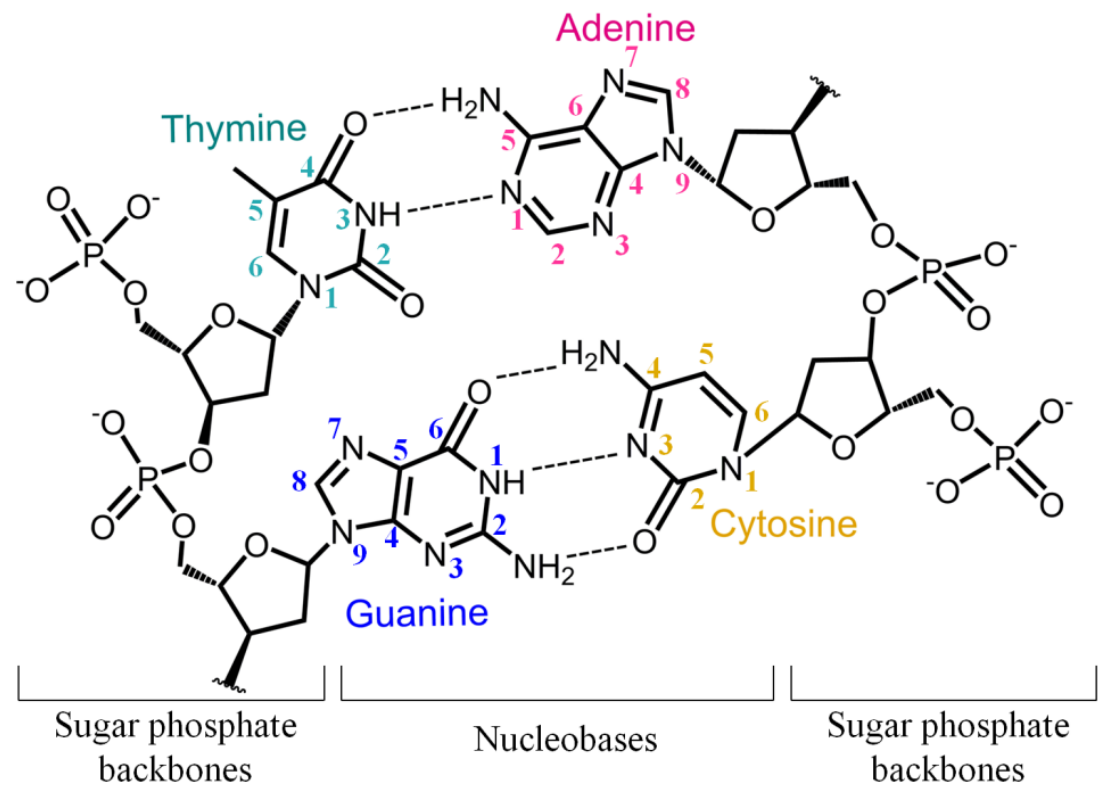

Figure 1: Chemical structure of DNA for adenine-thymine and guanine-cytosine base pairs. Dashed lines represent Watson-Crick H-bonds.

interaction could drive to a tailored use of ILs in various fields of life science. Several theoretical studies investigate the interaction of DNA with pure ILs and/or with IL/water solutions. Molecular dynamics simulation results suggest that both the groove binding mechanism of IL cations and their electrostatic association with DNA backbone contribute significantly to DNA stability ${ }^{20,21}$. However, no experimental findings are present in the literature in support of this hypothesis. DNA/IL systems are widely investigated by circular dichroism, fluorescence and UV/Vis spectroscopies ${ }^{19,22-24}$. However, these techniques provide information on the stabilizing or destabilizing effect of ILs on the DNA natural conformation, but do not provide detailed information on the molecular interactions causing such effects. A comprehensive experimental picture in terms of molecular interactions involved in DNA/ILs and the thermodynamics of the interaction process is still missing.

In the present work, we explore the thermal stability of DNA in water in presence of an increasing concentration of imidazolium-based chloride by synchrotron-based UV Resonance Raman (UVRR) scattering ${ }^{25}$. This technique represents a powerful tool for investigating the nature of inter-molecular interactions established between the IL cations and DNA bases. This is due to the selectively enhancement, in resonance conditions, of the vibrations mainly localized on nucleotides ring. This allows to minimize the Raman signals associated with the phosphate and sugar backbones, as well as those arising from buffer and solvent ${ }^{26-27}$, thus simplifying the complex Raman spectra of DNA. Moreover, the tunability of UV synchrotron radiation source permits a careful choice of the excitation wavelength in correspondence of the electronic transitions of specific nucleobases. Such approach allows to disentangle in a very efficient way the contributions arising from individual bases in the spectra of DNA ${ }^{28}$. In particular, the choice of $250 \mathrm{~nm}$ as excitation wavelength gives the opportunity to enhance and isolate the ring inplane vibration associated to the guanine residues ${ }^{29}$. This Raman feature is highly sensitive to the thermal disordering and it can be used as molecular marker of thermal denaturation of DNA.

\section{MATERIALS AND METHODS}

\subsection{Samples preparation}

1-Butyl-3-methylimidazolium chloride $\left(\left[\mathrm{C}_{4} \mathrm{MIM}\right] \mathrm{Cl}\right)$ was purchased by IoLiTec with a purity of $99 \%$. Before the use, IL was previously dried under vacuum with phosphorus pentoxide for $48 \mathrm{hs}$ in order to remove any water contamination.

DNA sodium salt from salmon testes (2000 base-pairs, CAS number 438545-06-3) was purchased by Sigma-Aldrich and used without further purification. The absence of proteins as contaminants ${ }^{30}$ was checked by measuring the absorbance ratio of a DNA solution at 260 and $280 \mathrm{~nm}$ that was found to be equal to 1.9. Trizma and Trizma-HCl were purchased by Sigma-Aldrich. For the preparation of solutions to be measured, a DNA stock solution of 
$1 \mathrm{mg} / \mathrm{mL}$ was prepared by dissolving dry DNA in Tris $10 \mathrm{mM}$ at $\mathrm{pH} 7.4$ and gently stirring for $24 \mathrm{~h}$ up to reaching a limpid solution. A detailed description of DNA/IL samples preparation is reported in Table 1:

Table 1: Description of DNA/IL samples preparation.

\begin{tabular}{|c|l|l|l|l|}
\hline & \multicolumn{1}{|c|}{ DNA in Tris } & \multicolumn{3}{|c|}{ DNA in [C ${ }_{4}$ MIM]Cl } \\
\hline DNA/IL & \multicolumn{1}{|c|}{$1 / 0(w / w)$} & \multicolumn{1}{|c|}{$1 / 22(w / w)$} & \multicolumn{1}{|c|}{$1 / 87(w / w)$} & \\
\hline Preparation & $250 \mu \mathrm{L}$ of DNA stock sol. & $250 \mu \mathrm{L}$ of DNA stock sol. & $250 \mu \mathrm{L}$ of DNA stock sol. & $250 \mu \mathrm{L}$ of DNA stock sol. \\
& $750 \mu \mathrm{L}$ of Tris & $\begin{array}{l}745 \mu \mathrm{L} \text { of Tris } \\
5 \mu \mathrm{L} \text { of }\left[\mathrm{C}_{4} \mathrm{MIM}\right] \mathrm{Cl}\end{array}$ & $10 \mu \mathrm{L}$ of Tris $\left[\mathrm{C}_{4} \mathrm{MIM}\right] \mathrm{Cl}$ & $\begin{array}{l}730 \mu \mathrm{L} \text { of Tris } \\
20 \mu \mathrm{L} \text { of }\left[\mathrm{C}_{4} \mathrm{MIM}\right] \mathrm{Cl}\end{array}$ \\
\hline
\end{tabular}

\subsection{UVRR scattering}

UVRR experiments were carried out at the BL10.2-IUVS beamline of Elettra Sincrotrone Trieste (Italy) ${ }^{25}$. UVRR spectra were excited at $250 \mathrm{~nm}$ by exploiting the UV emission provided by the synchrotron radiation (SR) source Elettra. UVRR spectra were recorded in back-scattered geometry by using a Czerny-Turner spectrometer (Trivista 557 , Princeton Instruments) with a spectral resolution of $\approx 15 \mathrm{~cm}^{-1}$. The radiation power on the sample was $\sim 20$ $\mu \mathrm{W}$. Any possible photo-damage effect due to a prolonged exposure of the sample to UV radiation was avoided by continuously spinning the sample cell during the measurements. For each sample, UVRR spectra were recorded in the temperature range from 305 to $370 \mathrm{~K}$. In order to compare the DNA spectra in presence and absence of ILs at a given temperature, the experimental profiles were normalized via the intensity of the $\mathrm{OH}$ stretching band of water at $\approx 3400 \mathrm{~cm}^{-1} 29,31$.

\section{RESULTS AND DISCUSSION}

Figure 2 shows the temperature-evolution of UVRR spectra excited at $250 \mathrm{~nm}$ and collected for DNA/IL $=1 / 22$ (w/w). In the wavenumber region between 1300 to $1800 \mathrm{~cm}^{-1}$, it is noteworthy the behaviour of the band centered at $\sim 1487 \mathrm{~cm}^{-1}$ and labeled as band I. This peak is mainly attributable to guanine residues ${ }^{29}$ arising from a combination of bending motion of $\mathrm{C} 8-\mathrm{H}$ and stretching movements of $\mathrm{C} 8=\mathrm{N} 7$ and N9-C 8 (see Figure 1$)^{27,31}$. Figure 2 shows an

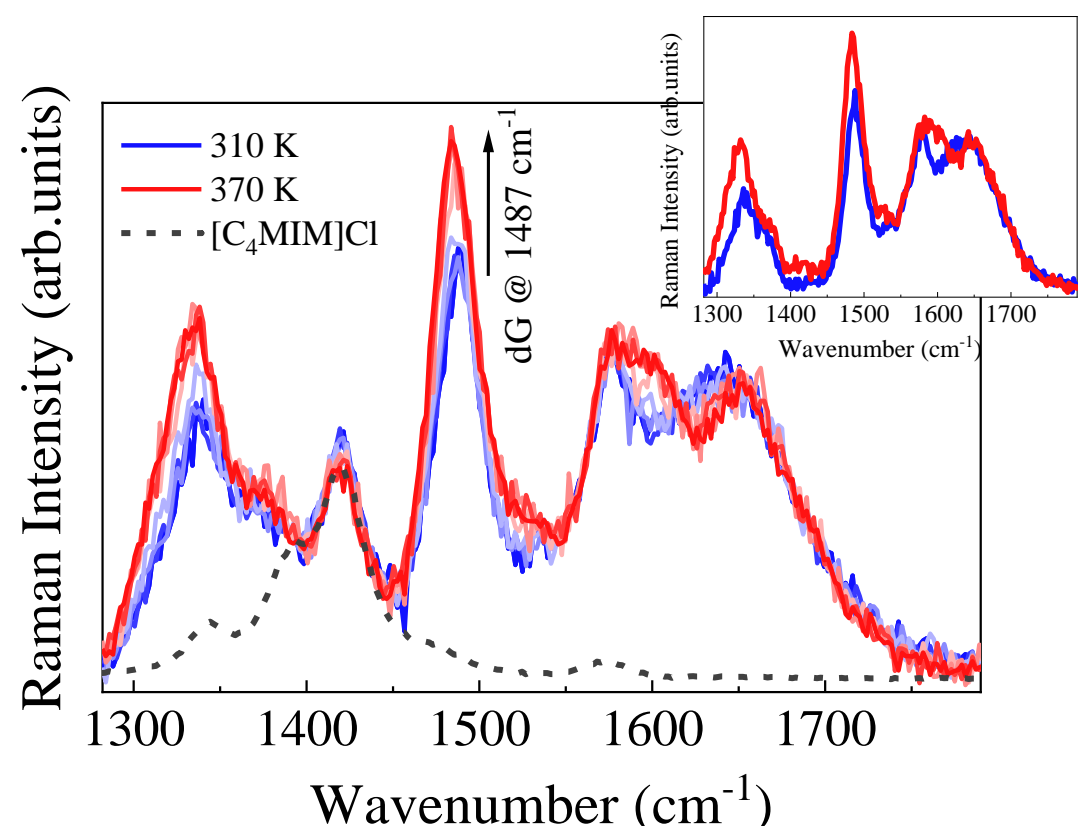

Figure 2: Temperature-evolution of UVRR spectra of DNA/IL (1/22 w/w). The dashed-lines represent the UVRR spectra of pure $\left[\mathrm{C}_{4} \mathrm{MIM}\right] \mathrm{Cl}$. Inset: Comparison between the UVRR spectra of DNA/IL $(1 / 0 \mathrm{w} / \mathrm{w})$ collected at 305 and $370 \mathrm{~K}$. 
increment of the intensity of the band I as a function of temperature both for DNA/IL $=1 / 22(\mathrm{w} / \mathrm{w})$ and for pristine DNA (see Inset of Figure 2). This trend, i.e. Raman hyperchromic effect ${ }^{32}$ recalls to the UV absorbance hyperchromism observed for DNA and it reflects the interdependence between the Raman scattering cross-section and the electronic absorption intensity. Consistently with UV absorbance, the increment of the Raman intensity of the aromatic ring vibrations of nucleotides is related to the thermal denaturation of DNA promoted by the increasing of temperature. This process has been ascribed, at molecular level, to two different effects: i) the disruption of vertical base-base stacking interactions and ii) the breakage of hydrogen bonds (HB) between Watson-Crick base pairs of DNA ${ }^{33-35}$.

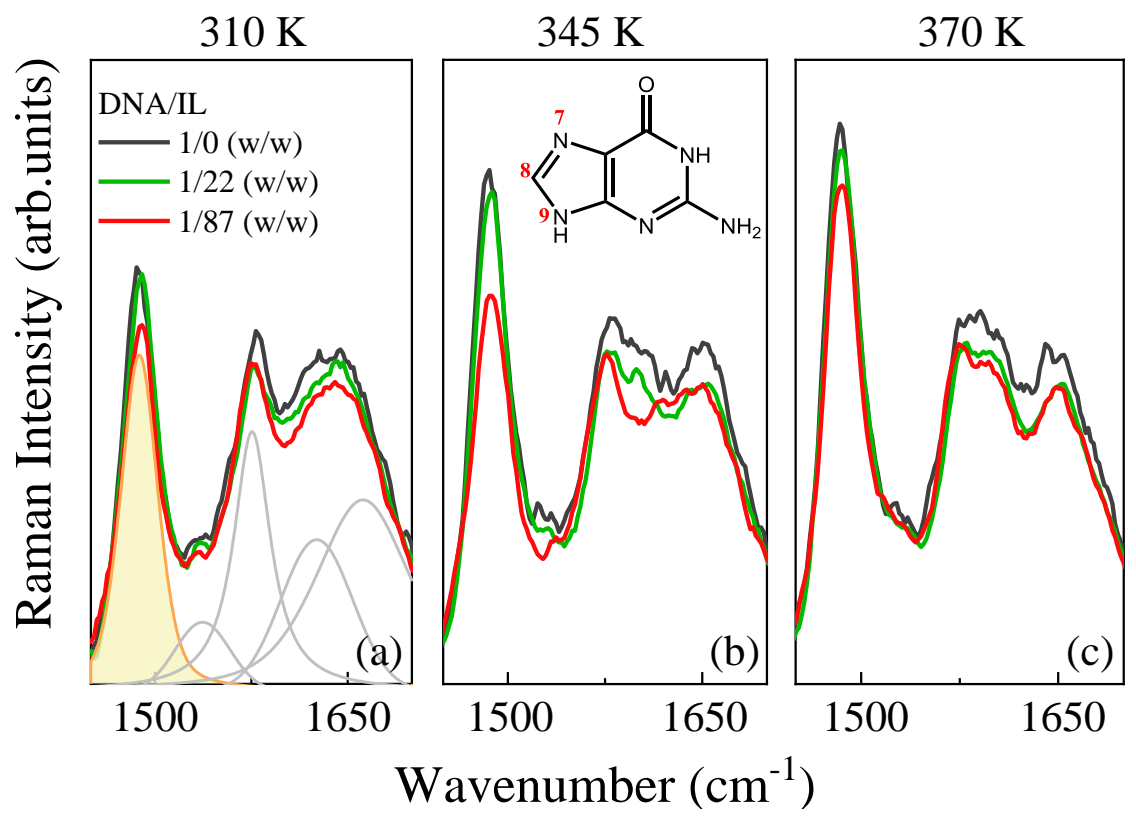

Figure 3: Comparison between the $250 \mathrm{~nm}$-excited Raman spectra of DNA/IL as function of concentration of [ $\left.\mathrm{C}_{4} \mathrm{MIM}\right] \mathrm{Cl}$ at $\mathrm{T}=310 \mathrm{~K}$ (a), $345 \mathrm{~K}$ (b) and $370 \mathrm{~K}$ (c) in the wavenumber range $1450-1700 \mathrm{~cm}^{-1}$. Representative fitting procedure is reported.

Figure 3 displays the variation in intensity undergone by band I as a function of the increasing concentration of $\left[\mathrm{C}_{4} \mathrm{MIM}\right] \mathrm{Cl}$ at three representative temperature. In order to better compare the spectra, the vibrational contribution of IL was subtracted from the total spectra of DNA+IL, after appropriate normalization on the intensity of the Raman signals assigned to the vibrational modes of $\left[\mathrm{C}_{4} \mathrm{MIM}\right] \mathrm{Cl}$ at 1021,1095 and $1213 \mathrm{~cm}^{-1}$. The reliability of this procedure is ensured by the fact that in the spectra region between 1000 and $1200 \mathrm{~cm}^{-1}$ Raman features arising from DNA are practically negligible with respect to the signals of IL. In order to extract more quantitative parameters that account the effect of IL concentration on the intensity of band I, a decomposition procedure of the spectra has been performed. An example of best- fitting procedure for the spectrum of DNA/IL $=1 / 87(w / w)$ collected at $310 \mathrm{~K}$ is reported in Figure 3 for the wavenumber range of interest.

Figure 4 shows the temperature-dependence of the UVRR intensity of the band I for pristine DNA and at different percentages of $\left[\mathrm{C}_{4} \mathrm{MIM}\right] \mathrm{Cl}$. As common feature to all the trends, it can be observed a sharp upturn for the intensity of the band $\mathrm{I}$ in correspondence of $\approx 340-350 \mathrm{~K}$. This temperature range is usually associated to the melting transition of DNA that involves the full denaturation of the double-stranded structure ${ }^{34,36}$. By inspection of Fig. 4, it is possible to observe that the intensities of band I for the spectra of DNA in presence of IL are less intense with respect to those measured in pure DNA over the whole investigated temperature range. This hypochromic effect suggests that the addition of $\left[\mathrm{C}_{4} \mathrm{MIM}\right] \mathrm{Cl}$ tends to favor the formation of a more compact structure in DNA doublestranded $^{29}$. Moreover, the persistence of hypochromicity also after the unfolding of DNA gives indication that the base-stacking of guanines is quite effective for DNA in the presence of $\left[\mathrm{C}_{4} \mathrm{MIM}\right] \mathrm{Cl}$. The plots in Figure 4 point out also a slight increment of the melting temperature observed for DNA as a consequence of the progressive addition of IL. In order to extract quantitative information, the intensity $I(T)$ of the band I can be properly described by a two state model $^{37}$ following the eqn: 


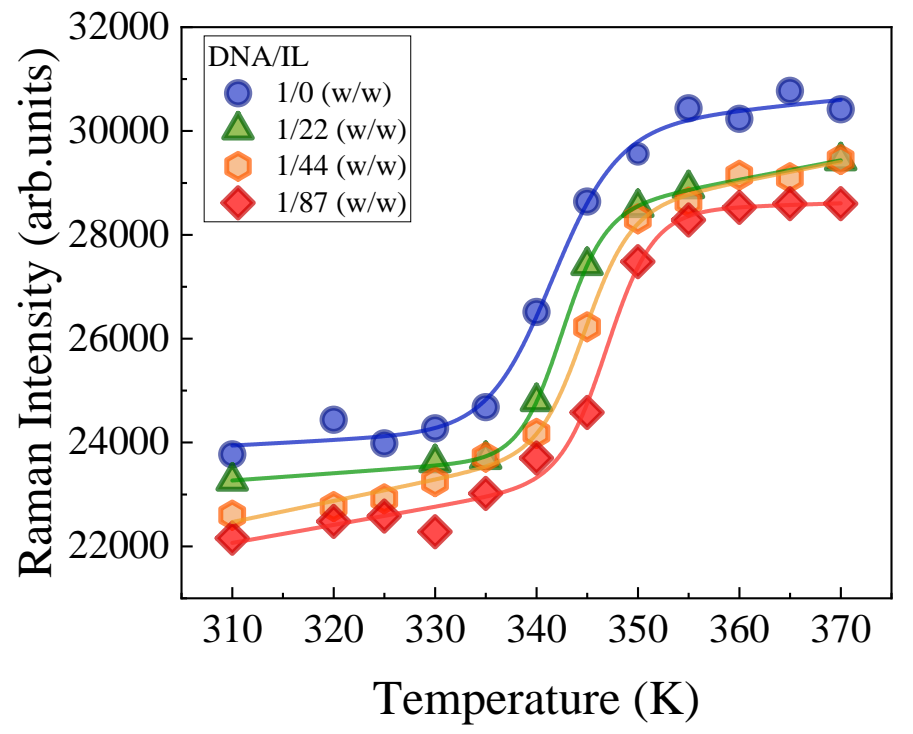

Figure 4: Temperature-dependence of the Raman intensity of the band I for DNA/IL (w/w) = 1/0 (blue circles), 1/22 (green triangles), 1/44 (orange hexagons), 1/87 (red rhombs). Continuous lines are fitting of the experimental data by using eqn. (1), see details in the text.

$$
I(T)=\frac{I_{N}+m_{N} \cdot T+\left(I_{D}+m_{D} \cdot T\right) K_{T}}{1+K_{T}},
$$

where $K_{T}$ signifies the equilibrium constant between native and denaturated states, $\mathrm{I}_{\mathrm{N}}$ and $\mathrm{I}_{\mathrm{D}}$ represent the intensities corresponding to the native and denaturated state of DNA, respectively. In the equation above, the parameters $\mathrm{m}_{\mathrm{N}}$ and $m_{D}$ describe the linear temperature-dependence of the band intensity in the pre and post-melting regions, respectively. Finally, the equilibrium constant native and denaturated states can be expressed as:

$$
K_{T=} \exp \left[\frac{\Delta H_{m}}{R}\left(\frac{1}{T_{m}}-\frac{1}{T}\right)\right],
$$

where $R$ is the gas constant and $\Delta H_{m}$ and $T_{m}$ are the enthalpy variation and the temperature associated to the melting process.

As visible in Figure 4, the temperature-dependence of the band I is satisfactorily reproduced by using eqn (1). The fitting procedure of plots in Figure 4 provides the estimation of the parameters $\Delta H_{m}$ and $T_{m}$, as summarized in Table 2.

Table 2: Thermodynamic parameters extracted by fitting the experimental data of Fig 4 with eqn (1) (see text for details).

\begin{tabular}{ccc}
\hline DNA/IL & $\boldsymbol{T}_{\boldsymbol{m}}(\mathrm{K})$ & $\Delta \boldsymbol{H}_{\mathrm{m}}(\mathbf{k J} / \mathbf{m o l})$ \\
\hline $1 / 0 \mathrm{w} / \mathrm{w}$ & $341.6 \pm 0.5$ & $3025.1 \pm 736.4$ \\
$1 / 22 \mathrm{w} / \mathrm{w}$ & $342.5 \pm 0.5$ & $4640.1 \pm 288.7$ \\
$1 / 44 \mathrm{w} / \mathrm{w}$ & $344.8 \pm 0.5$ & $4380.6 \pm 849.3$ \\
$1 / 87 \mathrm{w} / \mathrm{w}$ & $347.3 \pm 0.5$ & $5096.2 \pm 673.6$ \\
\hline \hline
\end{tabular}

The values reported in Table I confirm the slight increment of the melting temperature induced by the increasing concentration of $\left[\mathrm{C}_{4} \mathrm{MIM}\right] \mathrm{Cl}$, as already discussed above. This may be consistent with the results of theoretical investigations $^{20,21}$ suggesting that the cations of IL tend to majorly interact with the DNA backbone when the negative charges of phosphate groups are localized. This implies that the cations are able to stabilize the DNA structure by reducing charge repulsion between the phosphate groups on each of the DNA strands ${ }^{38}$. This stabilization effect is probably accompanied by the establishment of so-called $\mathrm{H}$-bond interactions between the $\mathrm{CH}$ groups of $\mathrm{IL}^{20}$ and the acceptor/donor sites present on the major and minor grooves of DNA. Overall these effects result in an enhancement of the stability of DNA native conformation also at higher temperature, promoted by the 
presence of IL. The presence of IL induces an increase of $\Delta H_{m}$ value with respect to the case of DNA/IL $=1 / 0$ $(\mathrm{w} / \mathrm{w})$. This result is in analogue with other investigation on melting parameter of DNA with divalent metal cations $^{38}$.

Beside the intensity change, Figure 4 points out also a slight red-shift for the band I upon the increasing of thermal motion. Figure 5 reports the wavenumber positions of band I found for pristine DNA and DNA+IL. Due to the normal composition of band I, the frequency of this Raman peak is sensitive to the interactions between the solvent molecules and the N7 site of guanine that can act as acceptor of H-bond ${ }^{39-40}$. The shift of the band I to lower frequency with the thermal denaturation has been attributed to a reinforcement of $\mathrm{H}$-bond formed by guanine with the solvent ${ }^{33}$. This phenomenon can be can be attributed to a major exposure of N7 site in denaturated DNA to solvent molecules. By the inspection of figure 5, we note that before the DNA thermal denaturation the presence of IL induces a slight blue-shift in the position of band I with respect to the case of pristine DNA. This result can be likewise explained by considering two effects: i) the formation of so-called H-bond interaction on $\mathrm{N} 7$ atom with $\mathrm{CH}$ groups of $\left[\mathrm{C}_{4} \mathrm{MIM}\right] \mathrm{Cl}^{20}$ and ii) the reduction of $\mathrm{H}$-bond interaction between buffer solvent molecules and N7 site due to the presence of cations of $\mathrm{IL}^{41}$. Since it is well-known the capacity of cations of IL to penetrate the "cone of hydration" of water molecules around the charged phosphate groups of $\mathrm{DNA}^{21}$, the diffusion of water across the nucleobases in DNA is hampered by the presence of IL. This is consistent with the slight blue-shift of band I observed in the samples of DNA+IL with respect to pure DNA before the melting temperature. The disappearing of this effect at high temperatures (see Figure 5) is probably due to the alteration of DNA structure caused by the melting process.

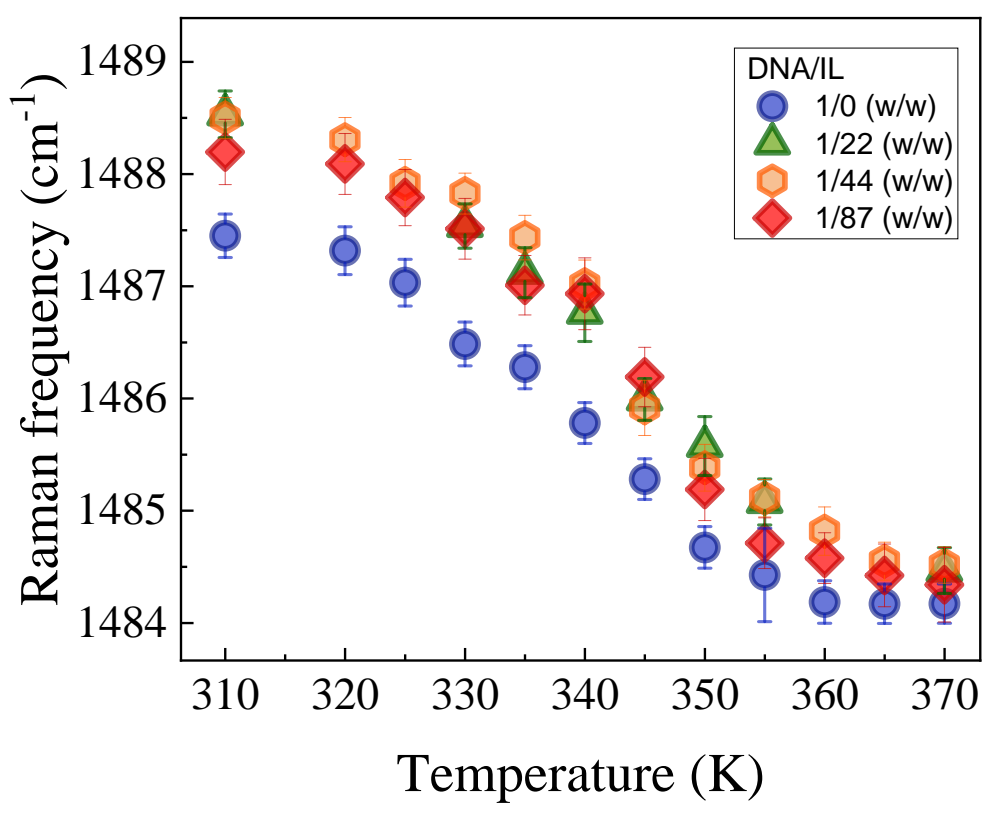

Figure 5: Temperature dependence of wavenumber position for the band I for pristine DNA and DNA+IL DNA/IL $(w / w)=1 / 0$ (blue circles), 1/22 (green triangles), 1/44 (orange hexagons), 1/87 (red rhombs).

\section{CONCLUSIONS}

We presented the results of synchrotron-based UVRR investigation on the temperature-dependent structural stability of DNA in presence of $\left[\mathrm{C}_{4} \mathrm{MIM}\right] \mathrm{Cl}$ as function of DNA/IL ratio. The choice of $250 \mathrm{~nm}$ as excitation wavelength gives the possibility to selectively enhance the vibrational signals associated to aromatic ring of guanine residues, then simplifying the complex off-resonance Raman spectra of DNA. The experimental data suggest that the thermal stability of DNA in IL is related at molecular level by two mechanisms: i) the unstacking of guanine bases and ii) the intermolecular interactions involving the $\mathrm{N} 7$ site of guanine. As main result, the thermal stability of DNA is found to increase as function of concentration of $\left[\mathrm{C}_{4} \mathrm{MIM}\right] \mathrm{Cl}$ in the investigated DNA/IL ratio range. 


\section{ACKNOWLEDGEMENTS}

The authors acknowledge the CERIC-ERIC Consortium for the access to experimental facilities and financial support.

\section{REFERENCES}

[1] Zhang, G. and Ma, Y. "Spectroscopic studies on the interaction of sodium benzoate, a food preservative, with calf thymus DNA," Food Chem., 141, 41-47 (2013).

[2] Yoshikawa, Y. "Effective chiral discrimination of tetravalent polyamines on the compaction of single DNA molecules," Angew. Chem., 52, 3712-3716 (2013).

[3] Kutzler, M. A. and Weiner, D. B., "DNA vaccines: ready for prime time?," Nat. Rev. Genet., 9, 776-788 (2008).

[4] Krishnan, Y. and Simmel, F. C., "Nucleic acid based molecular devices," Angew. Chem., 50, 3124-3156 (2011).

[5] Lukin, M. and de los Santos, C., "NMR Structures of Damaged DNA," Chem. Rev., 106, 607-686 (2006).

[6] Bonner G., and Klibanov, A. M., "Structural stability of DNA in nonaqueous solvents," Biotechnol. Bioeng., 68, 339-344 (2000).

[7] Arcella, A., Portella, G., Collepardo-Guevara, R., Chakraborty, D., Wales, D. J. and Orozco, M., "Structure and properties of DNA in apolar solvents," J. Phys. Chem. B, 118(29), 8540-8548 (2014).

[8] Singh, N., Sharma, M., Mondal, D., Pereira, M. M., and Prasad, K., "Very High Concentration Solubility and Long-Term Stability of DNA in an Ammonium-Based Ionic Liquid: A Suitable Medium for Nucleic Acid Packaging and Preservation," ACS Sustainable Chem. Eng., 5, 1998-2015 (2017).

[9] Nishimura, N., Nomura, Y., Nakamura, N. and Ohno, H., "DNA strands robed with ionic liquid moiety," Biomaterials, 26, 5558-5563 (2005).

[10] Wang, J. H., Cheng, D. H., Chen, X. W., Du, Z. and Fang, Z. L., "Direct extraction of double-stranded DNA into ionic liquid 1-butyl-3-methylimidazolium hexaflurophosphate and its quantification," Anal.1 Chem., 79, 620-625 (2007).

[11] Seddon, K. R., "Ionic Liquids for Clean Technology," J. Chem. Tech. Biotechnol., 68, 351-356 (1997).

[12] Welton, T., "Room-Temperature Ionic Liquids. Solvents for Synthesis and Catalysis," Chem. Rev., 99, 20712084 (1999).

[13] Hallett, J. P., and W. T., Chem. Rev., 111, 5, 3508-3576 (2011).

[14] MacFarlane, D. R., Pringle, J. M., and Howlett, F. M. "Ionic liquids and reactions at the electrochemical interface," Phys. Chem. Chem. Phys., 12, 1659-1669 (2010).

[15] Armand, M., Endres, F., MacFarlane, D. R. , Ohno, H. and Scrosati, B. "Ionic-liquid materials for the electrochemical challenges of the future," Nat. Mater., 8, 621-629 (2009).

[16] Xu, W, and Angell, C. A., "Solvent-free electrolytes with aqueous solution-like conductivities," Science, 302, 422-425 (2003).

[17] Welton, T."Ionic Liquids in Catalysis," Coord. Chem. Rev., 248, 2459-2477 (2004).

[18] de Zoysa, R. S. S., Jayawardhana, D. A., Zhao, Q. T ., Wang, D. Q., and Armstrong, D. W., "Slowing DNA translocation through nanopores using a solution containing organic salts," J. Phys. Chem. B, 113, 1333213336 (2009).

[19] Vijayaraghavan, R., Izgorodin, A., Ganesh, V., Surianarayanan, M. and MacFarlane, D. R. "Long-term structural and chemical stability of DNA in hydrated ionic liquids," Angew. Chem., 49, 1631-1633 (2010).

[20] Chandran, A., Ghoshdastidar, D. and Senapati, S. "Groove Binding Mechanism of Ionic Liquids: A Key Factor in Long-Term Stability of DNA in Hydrated Ionic Liquids?," J. Am. Chem. Soc., 134, 20330-20339, (2012).

[21] Jumbri, K., Abdul Rahman, M. B., Abdulmalek, E., Ahmad, H., and Micaelo, N., "An insight into structure and stability of DNA in ionic liquids from molecular dynamics simulation and experimental studies,"

Phys.Chem.Chem.Phys., 16, 14036-14041, (2014). 
[22] Mukesh, C., Mondal, D., Sharma, M. and Prasad, K.,, "Rapid dissolution of DNA in a novel bio-based ionic liquid with long-term structural and chemical stability: successful recycling of the ionic liquid for reuse in the process," Chem. Commun., 49, 6849-6851 (2013).

[23] Ding, Y., Zhang, L., Xie, J., and Guo, R., "Binding Characteristics and Molecular Mechanism of Interaction between Ionic Liquid and DNA," J. Phys. Chem. B, 114, 2033-2043 (2010).

[24] Hea, Y., Shanga, Y., Liua, Z., Shaob, S., Liua, H. and Hu, Y., "Interactions between ionic liquid surfactant [C12mim]Br and DNA in dilute brine," Colloids and Surfaces B : Biointerfaces, 101, 398-404 (2013).

[25] D’Amico, F., Saito, M., Bencivenga, F., Marsi, V., Gessini, A., Camisasca, G., Principi, E., Cucini, R., Di Fonzo, S., Battistoni, A., Giangrisostomi E. and Masciovecchio, C., "UV resonant Raman scattering facility at Elettra," Nucl. Instrum. Methods. Phys. Res., Sect. A, 703, 33-37 (2013).

[26] Chan, S. S., Austin, R. H., Mukerji, I. and Spiro, T. G., "Temperature-Dependent Ultraviolet Resonance Raman Spectroscopy of the Premelting State of dA*dT DNA," Biophysic. J., 72, 1512-1520 (1997).

[27] Perno, J. R., Grygon, C. A. and Spiro, T. G., "Ultraviolet Raman Excitation Profiles for the Nucleotides and for the Nucleic Acid Duplexes Poly(rA)-Poly(rU) and Poly(dG-dC)," J. Phis. Chem., 93, 5612-5678 (1989).

[28] Fodor, S. P. A., and Spiro, T. G., "Ultraviolet Resonance Raman Spectroscopy of DNA with 200-266-nm Laser Excitation," J. Am. Chem. Soc, 108, 3198-3205 (1986).

[29] Bianchi, F., Comez, L., Biehl, R., D’Amico, F., Gessini, A., Longo, A.M., Masciovecchio, C., Petrillo, C., Radulescu, A., Rossi, B., Sacchetti, F., Sebastiani, F., Violini, N. and Paciaroni, A., "Structure of human telomere G-quadruplex in the presence of a model drug along the thermal unfolding pathway," NAR, 46 (22), 11927-11938 (2018).

[30] Saenger, W. Principles of Nuclei Structure; Springer-Verlag : New York, 1984.

[31] Fodor, S.A.P., Rava, R. P., Hays, T. R. and. Spiro, T. G, "Ultraviolet Resonance Raman Spectroscopy of the Nucleotides with 266-, 240-, 218-, and 200-nm Pulsed Laser Excitation," J. Am. Chem. SOC., 107, 1520-1529 (1985).

[32] Tomlinson, B. and Peticolas, W. L., "Conformational Dependence of Raman Scattering Intensities in Polyadenylic Acid," J. Chem. Phys., 52, 2154 (1970).

[33] Duguid, J. G., Bloomfield, V. A., Benevides, J. M. and Thomas, G. J., "DNA Melting Investigated by Differential Scanning Calorimetry and Raman Spectroscopy," Biophys. J., 71, 3350-3360 (1996).

[34] Movileanu, L., Benevides, J. M. and Thomas, G. J., "Temperature Dependence of the Raman Spectrum of DNA. Part I-Raman Signatures of Premelting and Melting Transitions of Poly(dA-dT).Poly(dA-dT)," J. Raman Spectr., 30, 637-349 (1999).

[35] Movileanu, L., Benevides, J. M. and Thomas, G. J., "Temperature Dependence of the Raman Spectrum of DNA. Part II—Raman Signatures of Premelting and Melting Transitions of Poly(dA-dT)•Poly(dA-dT)," Biopolymers, 63, 181-194 (2002).

[36] Mukerji, I. and Williams, A. P., "UV Resonance Raman and Circular Dichroism Studies of a DNA Duplex Containing An A3T3 Tract: Evidence for a Premelting Transition and Three-Centered H-bonds," Biochemistry, 41, 69-77 (2002).

[37] Sassi, P., Giugliarelli, A., Paolantoni, M., Morresi, A. and Onori, G., "Unfolding and aggregation of lysozyme: A thermodynamic and kinetc study by FTIR spectroscopy," Biophys. Chem., 158, 46-53 (2011).

[38] Duguid, J. G., Bloomfield, V. A., Benevides, J. M., and Thomas, G. J., "Raman Spectroscopy of DNA-Metal Complexes. II. The Thermal Denaturation of DNA in the Presence of Sr2+, Ba2+, Mg2+, $\mathrm{Ca} 2+, \mathrm{Mn} 2+, \mathrm{C} 02+$, Ni2+, and Cd2+," Biophys. J., 69, 2623-2641 (1995).

[39] Nishimura, Y., Tsuboi, M., Sato, T. and Akoi, K., "Conformation-sensitive Raman lines of mononucleotides and their use in a structure analysis of polynucleotides: guanine and cytosine nucleotides," J. Mol. Struct., 146,123-153 (1986).

[40] Benevides, J. M. , Weiss, M. A. and Thomas Jr., G. J., "Design of the Helix-turn-helix motif: nonlocal effects of quaternary structure in DNA recognition investigated by laser Raman spectroscopy," Biochemistry, 30, 4381-4388(1991).

[41] Duguid, J. G. , Bloomfield, V. A., Benevides, J. M. and Thomas, G. J, "Raman Spectroscopy of DNA-Metal Complexes. 1. Interactions and Conformational Effects of the Divalent Cations: $\mathrm{Mg}, \mathrm{Ca}, \mathrm{Sr}, \mathrm{Ba}, \mathrm{Mn}, \mathrm{Co}, \mathrm{Ni}$, Cu, Pd, and Cd," Biophys. J., 65, 1916-1928 (1993). 